\section{Abstractions}

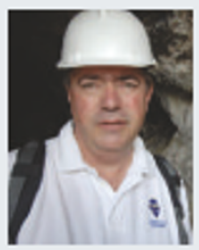

\section{FIRST AUTHOR}

Clive Finlayson, director of the Gibraltar Museum, has made it his mission to research Neanderthals, the Iberian peninsula's early inhabitants. Since 1997, he and his team have been excavating Gorham's Cave in Gibraltar. The fruits of their labour, revealed on page 850 , suggest that Neanderthals occupied the cave some $24,000-28,000$ years ago, making it one of their last strongholds. Finlayson spoke to Nature about the dig.

\section{Describe Gorham's Cave. Was it a} prehistoric 'Club Med'?

It must have been a great place. It faces the Mediterranean Sea, with the beach about 40-50 metres from the entrance. Pollen records show the climate wasn't bad either.

How hard was it to excavate? It's a massive cavern with archaeological deposits 18 metres thick. To reach it, you must go 350 steps down a cliff. Our results come from an areajust over 2 metres thick, which took us about 10 years to dig. I'm not going to be the one to finish the work being done there. I've already accepted that.

How did youcheckt hat modem cave-dwellers didn't contaminate the Neand erthal level? One of our many collaborators, Francisco Jimenez Espejo, works with marine cores drilled from the seabed. He drilled cores into the two critical levels: themodern and Neander thal. Analysis of 40 trace elements was done blindly and showed the chemical signature of each level to be uncontaminated.

What's the biggest mi sconception about Neand erthals?

People still think of Neanderthals as apemen without any kind of cognitive abilities, which is quite surprising as they survived for 300,000 years - muchlonger than we'veyet survived.

What were the final years like for the Neanderthals?

We think that climate had a lot to do with their dwindling numbers and eventual extinction. Neanderthals were used to a semi-wooded landscape. As the climate turned Europe into a more treeless tundra and steppe environment, the Neanderthals didn'tadapt well. By then, the populations were so small that any number of factors, such as disease, could have caused their ultimate extinction.

What's next?

We want to excavate the cave next door - trial excavations have confirmed that Neander thals lived there. And at the back of Gorham's Cave we hope to excavate a 30-metre nar row passageway, which might have been a burialsite. Who knows, maybe we'll be lucky and find more Neander thals.

MAKING THE PAPER

\section{Donald Campbell}

\section{The hunt for ice at the Moon's south pole.}

For years, some astronomers have been pushing the idea that there are large patches of ice at the Moon's poles. If confirmed, this ice could be useful for future lunar exploration efforts, acting as a resource for a permanent base, for example. But the paper on page 835 has dashed those hopes. It presents high-resolution radar images of the Moon's south pole - and finds no sign of ice. "Our results go against the hopes of many people," says Donald Campbell of Cornell University in Ithaca, New York, who led the study.

The idea that there might be ice on the Moon is perfectly reasonable. Comets or meteoroids could have brought water with them as they smashed into the lunar landscape. The slight tilt in the Moon's axis of rotation means that there are some areas at the poles - mainly craters - that are in constant shadow from the Sun. Here the temperature would be less than $-173^{\circ} \mathrm{C}$, more than low enough for any water to be frozen solid.

The concept was bolstered in 1992, when radar maps of Mercury indicated that there were large sheets of ice at its poles. And in 1994, the lunar orbiter Clementine sent back fairly low-resolution radar signals that suggested similar deposits of ice were present near the Moon's south pole.

The data gathered by Campbell and his team were obtained using the same principles as previous efforts. Radar waves are transmitted to the Moon's surface and the reflected wave is detected and analysed. The waves are scattered by rocks and soil, but are reflected back in a coherent pattern by ice. In addition, if the outgoing waves are polarized, ice will preserve the direction of polarization.

Campbell's team set out to image the Moon's south pole, and covered a larger area at higher

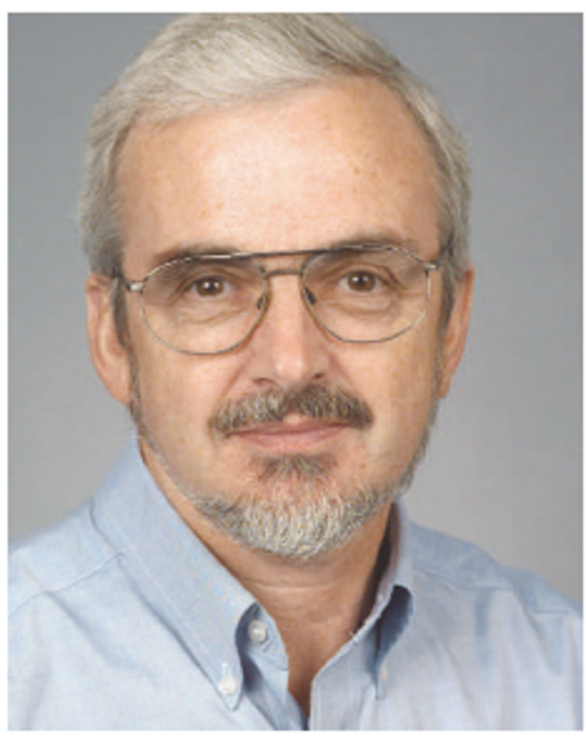

resolution than ever before. The outgoing radar signals were transmitted from the Arecibo telescope in Puerto Rico, and the reflected waves were picked up by a telescope in West Virginia seconds later.

"We had to resolve a lot of issues relating to the amount of available memory in computers" to deal with the data collected, says Bruce Campbell (no relation) of the Smithsonian Institution in Washington DC, who worked on the project. The team collected data in April and October 2005, and constructed the first images six months later. "Suddenly an image pops up. It is a very satisfying feeling," says Donald Campbell.

The team did find some features on the Moon that had radar-reflecting properties similar to the icy regions on Mercury. But unlike on Mercury, where these regions are all in shadow and so could be ice, the spots on the Moon were scattered randomly among sunny and shadowy regions. "These properties are not as unique to icy surfaces as we thought. That was a surprise," says Donald Campbell. If there is ice on the Moon, he adds, it is probably in the form of grains mixed in with the soil, and not in large patches.

\title{
KEY CONTRIBUTOR
}

The porous structure of zeolites makes them ideal for use as molecular sieves or catalysts for chemical reactions. Working at the Polytechnic University of Valencia in Spain, a team led by Avelino Corma has been working to exp and the uses for zeolites by synthesizing materials with large pores and interconnected channels.

The researchers had established that, by using germanium in the framework and the smallorganic compound hexamethonium as a structure-directing agent, they could generate crystals with the pore size they were after. But the syntheses resulted in crystals with varying structures and pore sizes. "Many different structures could crystallize," says Corma.

Sothe chemists turned to high-throughputsynthesis in an attempt to identify a reaction and product that would meet their requirements. PhD student Manuel Moliner subsequently ran 193 differentsyntheses, expanding the parameters and conditions beyond his adviser's remit. The result, described on page 842, was ITQ-33, a zeolite with extra-large pores that are linked together by perpendicular channels. "Manuel's boldness to test rather unusual synthesis conditions was rewarded with ITQ-33," says Corma.

The team has already shown that ITQ-33 can be used to generate more diesel and propylene, and less gasoline, from gasoil. 